\title{
DESCARGAS ATMOSFÉRICAS E O OLHAR GEOGRÁFICO: ESTUDO DE CASO DAS OCORRÊNCIAS NA BACIA HIDROGRÁFICA DO RIO PARAÍBA DO SUL (SÃO PAULO) E IMPLICAÇÓES NA SOCIEDADE
}

\author{
ATMOSPHERIC DISCHARGES AND THE GEOGRAPHIC ASPECT: \\ CASE STUDY OF THE OCCURRENCES IN THE HYDROGRAPHIC \\ BASIN OF THE PARAÍBA DO SUL (SÃO PAULO) RIVER AND \\ IMPLICATIONS IN THE SOCIETY \\ RELÁMPAGOS Y EL ASPECTO GEOGRÁFICO: ESTUDIO DE CASO \\ DE LAS OCURRENCIAS EN LA CUENCA DEL RIO PARAÍBA DO \\ SUL(SP) E IMPLICACIONES EN LA SOCIEDAD
}

Elder Bortolin elderbortolin.usp@gmail.com

Emerson Galvani

Universidade de São Paulo

Faculdade de Filosofia, Letra e Ciências Humanas

Departamento de Geografia

egalvani@usp.br

Resumo: Realizou-se um estudo da ocorrência de descargas atmosféricas, popularmente conhecidas como raios, na regiáo de maior ocorrência do fenômeno dentro da Bacia Hidrográfica do Rio Paraíba do Sul (São Paulo), em descargas por km²/ano. Analisaramse as formas e implicaçôes dessas ocorrências na sociedade com base nos números e nas circunstâncias dos óbitos. A base de dados utilizadas foi obtida junto ao Grupo de Eletricidade Atmosférica (ELAT) em uma série temporal de 13 anos, analisando o período de 1998 a 2011. Como resultados, foi possível observar regiōes com maior incidência de relâmpagos dentro da área analisada. E também foi possível, dentro desse recorte, visualizar os municípios onde se tem as maiores ocorrências de óbitos por descargas atmosféricas. Análises de como ocorrem esses óbitos, quais são as circunstâncias e quais são os potenciais fatores que colocam a populaçáo em risco, também entram nos resultados alcançados. A principal causa do elevado número de óbitos por descargas atmosféricas no país ainda é reflexo de uma falta de conscientização da população com relação às formas 
de manifestação desses fenômenos elétricos da atmosfera, bem como das formas de se proteger dos mesmos. Os avanços no entendimento de como ocorrem as fatalidades por descargas atmosféricas no país ajudam a direcionar medidas de proteção para a população. Ao entender a dinâmica das ocorrências de óbitos, é possível criar políticas de prevenção e materiais educativos voltados para a realidade nacional. Se os maiores números de óbitos ocorrem no setor rural, com trabalhadores do campo, é possível direcionar programas de proteção para esse setor da sociedade.

Palavras chave: Descargas Atmosféricas, Relâmpagos, Tempestades, Rio Paraíba do Sul, Óbitos.

Abstract: We conducted a study of the occurrence of atmospheric discharges, popularly known as rays, in the region of highest occurrence of the phenomenon within the Hydrographic Basin of the Paraíba do Sul (São Paulo), in flashes per $\mathrm{km}^{2} /$ year. The forms and implications of these occurrences in society were analyzed on the basis of the numbers and circumstances of the deaths. The data base was obtained from the Atmospheric Electricity Group (ELAT) in a time series of 13 years, analyzing the period from 1998 to 2011. As a result, it was possible to observe regions with the highest incidence of lightning within the analyzed area. It was also within this clipping, view the counties where we have the highest occurrences of death by lightning. Analysis of how these deaths occur, what are the circumstances and what are the potential factors that put the population at risk, also enters the achievements. The main cause of the high number of deaths due to atmospheric discharges in the country still reflects a lack of awareness of the population regarding the manifestations of these electrical phenomena of the atmosphere, as well as ways of protecting themselves from them. The advances in the understanding of how the fatalities due to atmospheric discharges in the country help to direct measures of protection for the population. By understanding the dynamics of death occurrences, it is possible to create prevention policies and educational materials geared to the national reality. If the largest numbers of deaths occur in the rural sector, with farmers, it is possible to target protection programs for this sector of society.

Key-words: Atmospheric Discharges, Lightning, Storms, Rio Paraiba do Sul, Deaths.

Resumen: Estudio de la ocurrencia de los relámpagos, popularmente conocida como rayos, en la región de mayor ocurrencia del fenómeno dentro de la cuenca hidrográfica del Río Paraíba do Sul, en las descargas por cuadrado km / año. El análisis de las formas y las consecuencias de estas ocurrencias en la sociedad sobre la base de los números y las circunstancias de las muertes. Como resultado, fue posible observar regiones con la mayor incidencia de un rayo en la zona analizada. También era posible, dentro de este corte, ver las ciudades donde tenemos las más altas incidencias de muertes por un rayo. El análisis de cómo se producen estas muertes, cuáles son las circunstancias y cuáles son los posibles factores que ponen a las personas en situación de peligro, también entran en los resultados. La principal causa del elevado número de muertes por rayos 
en el país sigue siendo un reflejo de la falta de conciencia pública con respecto a las manifestaciones de estos fenómenos eléctricos en la atmósfera, así como maneras de protegerlos. Los avances en la comprensión de cómo las víctimas mortales se producen por un rayo en el país ayudan a las medidas de protección directa para la población. Mediante la comprensión de la dinámica de los casos muertes, es posible crear políticas de prevención y materiales educativos orientados a la realidad nacional. Si un mayor número de muertes se producen en las zonas rurales, con los trabajadores en el campo, es posible dirigir los programas de protección para este sector de la sociedad.

Palabras clave: Relámpago, Rayos, Tormentas, Río Paraíba do Sul, Muertes.

\section{INTRODUÇÃO}

$\mathrm{Na}$ história da humanidade e nas mais diversas culturas, fenômenos naturais que se mostravam implacáveis, extraordinários e que causavam grande temor e respeito, eram sempre relacionados à fúria de deuses, cujo objetivo era julgar e castigar aquelas sociedades que não estariam cumprindo seus desejos e vontades. Com o progresso da ciência, se colocando como fonte de explicação racional para o entendimento do mundo, essas crenças cederam espaço a conceitos e teorias científicas.

Os estudos dos fenômenos atmosféricos, ao longo da história da ciência, evoluíram em larga escala nos diversos ramos acadêmicos: Física, Geografia, Biologia, Oceanografia, Meteorologia, entre outros.

Os relâmpagos impactam na sociedade de muitas formas, com perdas econômicas, materiais, mas principalmente perdas humanas, vidas que são perdidas anualmente por descargas atmosféricas.

Ao analisar as ocorrências de óbitos por raios, este artigo faz uma exposição das tendências e padrôes que nos permitem saber quem são as vítimas, ou seja, que segmentos da sociedade são mais vitimados por essas descargas atmosféricas.

Os avanços que se obtém ao analisar as tendências futuras do fenômeno, em conjunto com a coleta e observação dos dados de óbitos por relâmpagos, é a chave que nos permite, desde já, planejar políticas públicas de orientação e prevenção para a populaçáo, que ainda hoje é vitimada por muitas vezes se deixar levar por superstiçóes e crenças.

\section{REFERENCIAL TEÓRICO}

O Brasil, com suas dimensóes continentais, posicionado na região tropical do globo, está sujeito a uma enorme quantidade de raios por ano. Com uma proporção maior durante os períodos quentes e chuvosos do veráo, anualmente as descargas atmosféricas fatalizam centenas de pessoas. Na maioria das vezes, o pouco conhecimento sobre o fenômeno e a crença em superstições e mitos são as principais condicionantes para esse elevado número de óbitos. 
A escolha da região levou em consideração a possibilidade de atribuir um recorte que permitisse fazer uma análise tanto da ocorrência do fenômeno em si como observar também o número de óbitos. O recorte inicial assumido foi toda a Bacia Hidrográfica do rio Paraíba do Sul. Dentro da bacia, os dados nos apresentaram regióes de maior interesse, ou seja, apresentavam maiores incidências de descargas atmosféricas. Essas ocorrências são de proporçôes tão elevadas quanto as que ocorrem nas regiōes de maior incidência de relâmpagos no país, tais como o interior no Rio Grande do Sul e principalmente na região norte, com destaque no estado do Amazonas. Portanto, a área de análise desta pesquisa se limitou por dois trechos dentro da bacia do rio Paraíba do Sul. Toda a região do Vale do Paraíba do Sul, situada no estado de São Paulo, foi analisada em conjunto com a região do Médio Paraíba do Sul, que foi limitada na região de confluência do rio Paraíba do Sul com o rio Preto e Paraibuna, que ocorre no município fluminense de Três Rios. Assim como, essa região de pesquisa, foi possível incorporar na análise dois elementos importantes. O município com o maior número de ocorrências de descargas atmosféricas foi incluído neste trabalho, bem como também foi possível analisar uma região com municípios de grande densidade demográfica e forte desenvolvimento econômico, tanto industrial como agropecuário, que é a região do Vale do rio Paraíba do Sul.

Os relâmpagos são correntes elétricas de alta intensidade que ocorrem na atmosfera com duração típica de meio segundo, contendo uma trajetória em torno de 5 a $10 \mathrm{~km}$. Possui ramificações que podem se estender tanto na vertical como na horizontal.

O relâmpago é uma descarga elétrica de grandes proporçóes que ocorre na troposfera da Terra como consequência da eletrificação (separação de cargas elétricas) das chamadas nuvens de tempestade ou cumulonimbus. Tais nuvens apresentam elevado desenvolvimento vertical e horizontal, formação de gelo em altas altitudes (acima de $5-6 \mathrm{~km}$ ) e fortes correntes verticais de vento (MACGORMAN, RUST, 1998; RAKOV, UMAN, 2003; NACCARATO, 2005).

A formação do aspecto visual de um relâmpago é devido ao rápido movimento dos elétrons de um ponto a outro (PINTO JR.; PINTO, 2008). Sua aparência sugere que ele seja uma descarga contínua, porém são curtos pulsos com duração de dezenas a centenas de microssegundos ${ }^{1} \mathrm{e}$ intensidade de até centenas de milhares de ampères ${ }^{2}$, bem como de correntes com lentas variaçôes com duração de dezenas a centenas de milissegundos ${ }^{3}$ e intensidade de até centenas de ampères (PINTO JR.; PINTO, 2008).

É com a separação das cargas dentro das nuvens que surge um campo elétrico que é capaz de romper a rigidez dielétrica do ar. O relâmpago é o momento da ruptura, que ocorre em pontos específicos da nuvem, como uma forma de equilibrar novamente as cargas elétricas na atmosfera.

Um microssegundo equivale a um milionésimo de segundo.

Unidade de medida do SI de intensidade de corrente elétrica.

Um milissegundo equivale a um milésimo de segundo. 
Com o acúmulo de cargas, o campo elétrico intensifica-se dando origem às descargas atmosféricas ou relâmpagos, causados pela ruptura dielétrica do ar no interior da nuvem de tempestade (NACCARATO, 2001).

Ocorrem predominantemente em nuvens cumulonimbus, típicas de tempestades, mas podem ser observados em tempestades de areia ou neve, bem como em erupçóes vulcânicas, além de ser capaz de produzi-los artificialmente.

A terminologia raio é utilizada apenas para nomear a descarga elétrica que atinge o solo. "Raio é a designação coloquial para o caminho luminoso da descarga atmosférica, às vezes utilizada, mais formalmente, para designar uma descarga para o solo. ” (MENDES JR.; DOMINGUES, 2002).

Os fatores que irão definir de que tipo é um relâmpago será o ponto em que ele se originou e o ponto em que ele se extinguiu.

Podemos fazer uma divisão em dois grandes grupos de descargas atmosféricas:

I) Manifestam-se somente na atmosfera, ou seja, o início e o fim ocorrem no ar;

II) Atingindo o solo;

Dentro da primeira categoria (I) é possível fazer uma subdivisão em três tipos de relâmpagos;

a) Os relâmpagos que se originam na nuvem e terminam em algum ponto do ar.

b) Relâmpagos que se iniciam em uma nuvem e terminam em outra nuvem

c) Relâmpagos que ocorrem dentro da nuvem.

São os relâmpagos mais frequentes que ocorrem no planeta. Representam cerca de 70\% da quantidade total de descargas atmosféricas (PINTO JR.; PINTO, 2008). Essa alta frequência é basicamente relacionada ao fato de a capacidade isolante do ar diminuir com a altura, como também à maior proximidade de centros de carga de polaridades opostas (PINTO JR.; PINTO, 2008). Porém, essa proporçáo tende a variar conforme se varia a latitude, ou seja, temos uma maior ocorrência em regióes de baixas latitudes e menor nas regiôes de médias latitudes (PINTO JR.; PINTO, 2008).

Na segunda categoria (II) há mais dois tipos de relâmpagos:

a) Relâmpagos Solo - Nuvem;

b) Relâmpagos Nuvem - Solo;

De todos os tipos, este é o mais perigoso e devastador para o homem e suas atividades. Ocorrem em número bem menor do que os relâmpagos entre nuvens e dentro das nuvens (PINTO JR.; PINTO, 2008). Porém, na relaçáo dos que atingem o solo, 99\% são desse tipo, o que torna os relâmpagos solo-nuvem muito raros (PINTO JR.; PINTO, 2008). Sua duração varia de um décimo de segundo podendo chegar até dois segundos, mantendo uma média de um terço de segundo. A corrente elétrica sofre 
bastante alteração durante a descarga, mas tem seus máximos, na maior parte dos casos, entre 20.000 a 30.000 ampères (PINTO JR.; PINTO, 2008). Essa corrente flui por um canal de poucos centímetros de diâmetro e a temperatura pode atingir valores superiores a $30.000{ }^{\circ} \mathrm{C}^{4}$ (PINTO JR.; PINTO, 2008).

Dentro desta categoria, podemos agrupar esses dois tipos de relâmpagos em positivos ou negativos. O que basicamente irá definir se um raio será negativo ou positivo é a polaridade das cargas elétricas que são transferidas efetivamente para o solo. Portanto:

i) Negativo: Transfere cargas negativas para o solo;

ii) Positivo: Transfere cargas positivas para o solo;

Figura 1 - Desenho esquemático simplificado dos tipos de relâmpagos que atingem o solo: a) Nuvem - Solo positivo; b) Nuvem - Solo negativo; c) Solo - Nuvem positivo; d) Solo - Nuvem negativo
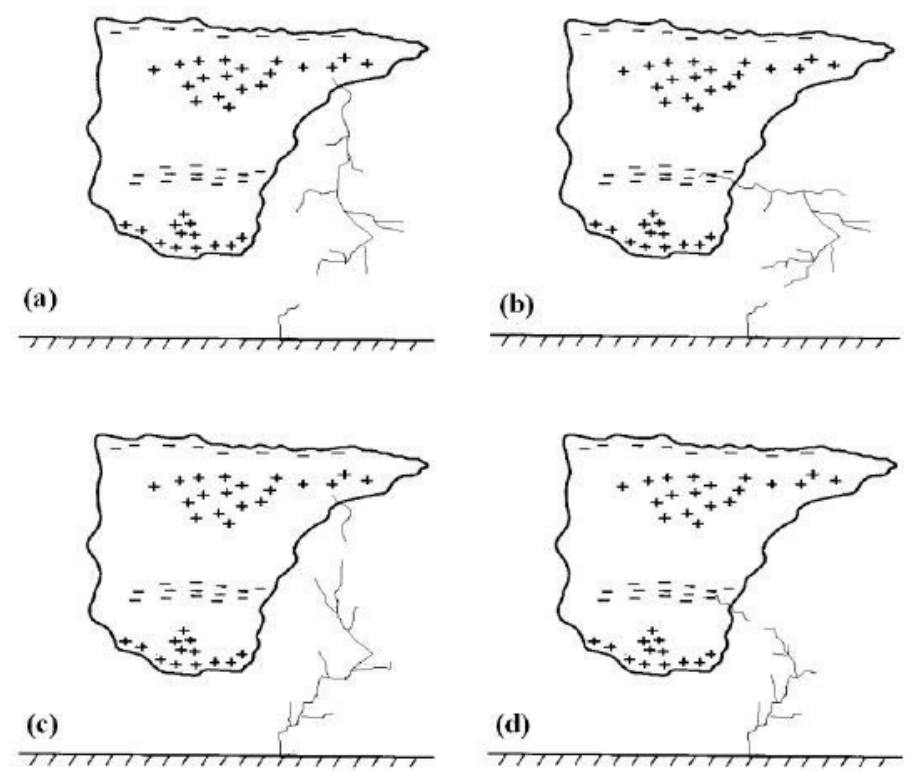

FIGURA 4.3 - Desenho esquemático simplificado dos tipos de relâmpagos que atingem o solo: (a) NS positivo; (b) NS negativo; (c) SN positivo; (d) SN negativo. FONTE: Naccarato (2001).

Fonte: Naccarato (2001).

As cumulonimbus são as principais nuvens geradoras de relâmpagos, mas há casos de descargas atmosféricas ocorrerem também de nuvens stratocumulus ou ninbostratus. (PINTO JR.; PINTO, 2008). É característica das cumulonimbus a grande extensão vertical com fortes correntes verticais de ar, fazendo com que essas nuvens possuam grande tamanho e consigam alcançar elevada altura. De acordo com o INPE/ELAT

4 Essa temperatura equivale a cinco vezes a temperatura da superfície do Sol. 
(2014), em qualquer instante, cerca de duas mil tempestades estáo ocorrendo ao redor do mundo, isto equivale a cerca de 50 mil tempestades ocorrendo todo dia ou cerca de 16 milhóes por ano.

\section{ÁREA DE ESTUDO E PROCEDIMENTOS DE ANÁLISE}

Sobre a área de estudo, os limites da bacia hidrográfica, bem como os municípios integrantes foram extraídos do CEIVAP e dos comitês estaduais de SP, MG e RJ. A bacia do rio Paraíba do Sul se estende por três estados na regiáo sudeste do Brasil. O principal rio da bacia, o Paraíba do Sul, tem a sua nascente no município de Paraibuna, no estado de Sáo Paulo, na área de represamento e confluência dos rios Paraitinga e Paraibuna, na Serra da Bocaina. Com uma área de drenagem de aproximadamente $62.074 \mathrm{~km}^{2}$, essa bacia é considerada, em superfície, a terceira maior bacia de categoria secundária do país (CEIVAP, 2017).

\section{Figura 2 - Mapa da Bacia Hidrográfica do Rio Paraíba do Sul}

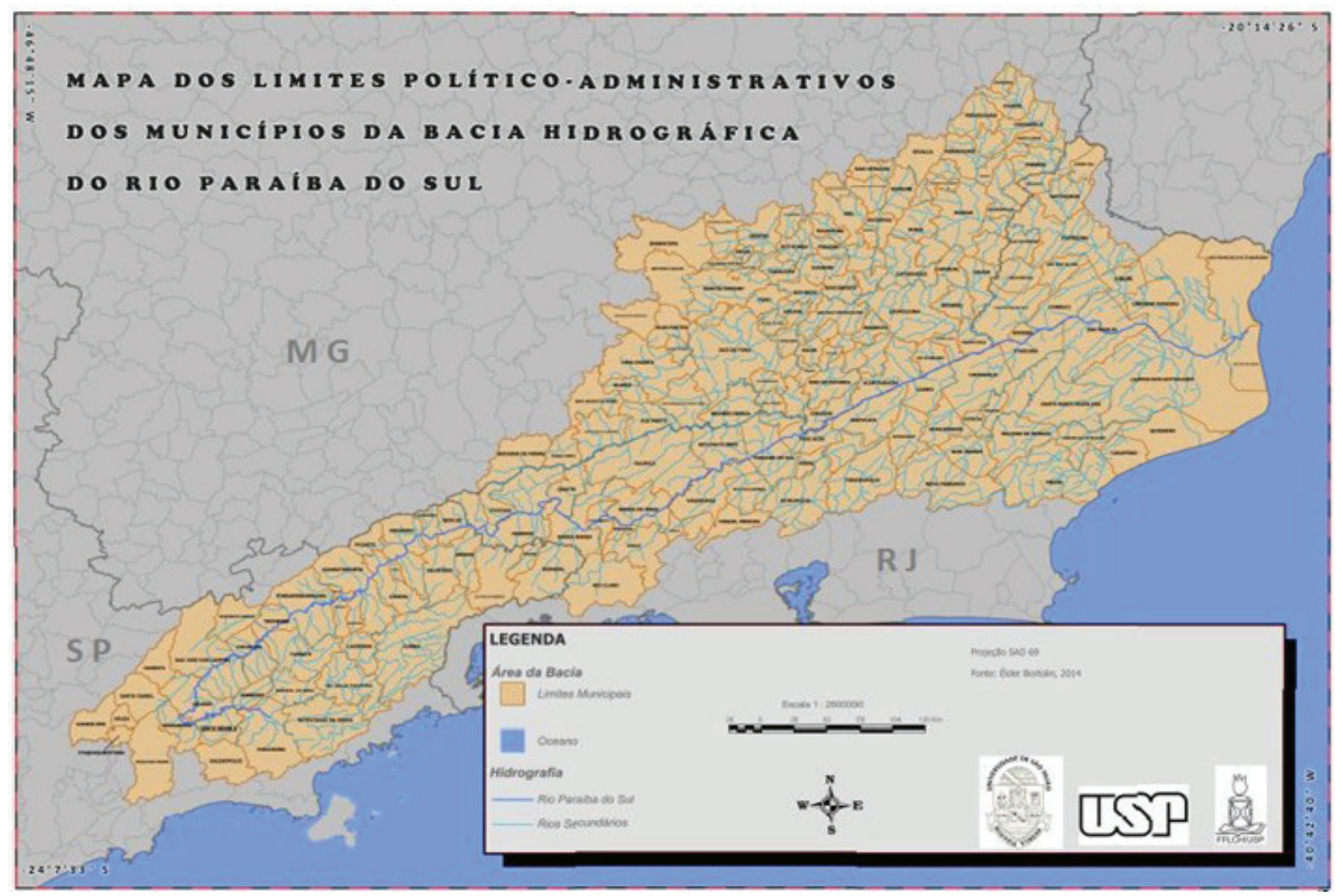

Fonte: do autor.

No que se refere às características geomorfológicas da bacia, ela está situada sobre o cinturão orogênico, dentro da unidade de planaltos e serras do Atlântico leste sudeste. O cinturão orogênico do Atlântico estende-se desde a parte oriental da região Nordeste até o sudeste do Estado do Rio Grande do Sul (ROSS, 2008). É uma faixa 
de grande complexidade litológica e estrutural, prevalecendo rochas metamórficas de diferentes tipos e idades, como gnaisses, migmatitos, quartzitos, micaxistos, filitos e, secundariamente, intrusivas, como os granitos e os sienitos (ROSS, 2008).

A zona climática que influi pela região da bacia é predominantemente tropical quente e úmida. A altitude nas áreas serranas irá interferir no fluxo dos ventos bem como no regime das chuvas na regiáo. Portanto, um forte efeito orográfico, que irá proporcionar uma quantidade de chuvas maior nas encostas a barlavento da Serra do Mar e da Serra da Mantiqueira. Já a regiáo no Vale do Rio Paraíba do Sul irá apresentar maiores temperaturas e menor umidade.

A individualizaçâo geomorfológica do Vale do Paraíba é acompanhada de uma feiçáo climática especial. Apresenta-se como uma faixa de menor umidade e temperaturas mais elevadas entre as serras do Mar e da Mantiqueira. Os valores pluviométricos anuais da ordem de 3000 $\mathrm{mm}$ nesta última decrescem no vale para 1100 e $1400 \mathrm{~mm}$, chegando mesmo, em certos trechos, a índices inferiores a $1100 \mathrm{~mm}$. Numa área de predominância de atuaçáo da onda de leste a descida do ar vindo do oceano, já aliviado de boa parte de sua umidade pela precipitaçáo ocorrida na subida da serra e sobre o planalto, é explicação suficiente a este caráter. Pelas técnicas usuais de análise, a classificaçáo climática do Vale do Paraíba é associada à Bacia Paulistana. Náo obstante ostentarem, ambos, semelhanças de quantidade e número de dias de chuva no ano e nos dois períodos, a análise rítmica revela uma importante diferenciaçáo no inverno. Náo só o Vale do Paraíba é mais seco do que a área da Metrópole, exibindo índices equivalentes a cerca da metade daqueles ocorridos nesta última área, como também quanto aos graus de resfriamentos produzidos pelas invasōes polares. A Bacia Paulistana está mais frequentemente sujeita às ondas de frio, seja pela latitude mais favorável, seja pela repercussão das passagens canalizadas pelo litoral, além do que o grau dos resfriamentos é maior. (MONTEIRO, 1973).

Por ser uma região de clima transicional, muito influenciada pelo regime das massas de ar polar vindas da regiáo sul do país, associadas com a atuaçáo da massa tropical atlântica que carrega a região com umidade do oceano, há uma elevação dos índices pluviométricos. Uma grande parte precipita sobre a Serra do Mar, nas regióes do maciço do Itatiaia e na Serra dos Órgãos, onde a precipitação pode chegar a valores superiores a $2.000 \mathrm{~mm}$. Os menores totais, que oscilam entre 1.000 e $1250 \mathrm{~mm}$, são observados em uma estreita faixa do Médio Paraíba do Sul e no curso inferior da bacia hidrográfica (AGEVAP, 2006). De acordo com Conti (1975), a proximidade com o litoral proporciona a essa região uma considerável influência decorrente da umidade oriunda do Oceano Atlântico. Entretanto, o Vale do Rio Paraíba do Sul no trecho paulista localiza-se em uma faixa transicional, onde existe alternância dos sistemas atmosféricos. Assim, os eventos pluviométricos são condicionados fortemente pela ação das frentes. Entretanto, embora a gênese das chuvas esteja relacionada à existência das frentes, o relevo tem muitas vezes papel determinante na intensidade e distribuição espacial dessa precipitaçáo. 
Um dos maiores polos industriais do País está situado na regiāo do Vale do Paraíba do Sul. Grandes indústrias dos segmentos, químico, metalúrgico, farmacêutico, de eletrônicos e de telecomunicações, compóem quase 50\% do PIB da UGRHI 02 (SMA, 2011).

Os dados de incidência de relâmpagos aqui utilizados, foram obtidos do Grupo de Eletricidade Atmosférica do INPE 5 (ELAT). Uma análise preliminar dos dados obtidos, mostrou uma regiáo dentro da bacia do rio Paraíba do Sul com uma forte ocorrência de descargas atmosféricas. Como o que se pretende mostrar neste estudo são as implicações e os impactos dos raios na sociedade, optou-se por escolher essa região, que compreende a região do Vale do Paraíba do Sul, no estado de São Paulo até a região do Médio Paraíba do Sul, limitada na confluência do rio Paraíba do Sul com o rio Preto e Paraibuna no município fluminense de Três Rios. Com essa região também é possível abranger o município de Porto Real, que apresenta o maior número de descargas atmosféricas por $\mathrm{km}^{2}$ por ano no período de 1998 a 2011.

Para os dados de descargas atmosféricas, a fonte é o sensor orbital LIS, que se encontra a bordo da plataforma Tropical Rainfall Measuring Mission (TRMM). Essa plataforma está em missão conjunta entre a agência espacial americana NASA e a agência espacial japonesa JAXA. ${ }^{6}$ O período de coleta dos dados está entre 1998 e 2011. Ainda segundo o ELAT, os dados foram trabalhados e corrigidos com a colaboraçáo da pesquisadora Dra. Rachel I. Albrecht da Divisão de Satélites e Sistemas Ambientais (DSA/CPTEC) do INPE.

Os mapas 9 e 10 são o resultado da espacialização das variáveis de incidências de descargas atmosféricas e de óbitos organizados e reunidos pelo Grupo de Eletricidade Atmosférica, o ELAT. O mapa de densidade demográfica foi produzido utilizando os dados do Censo 2010, realizado pelo IBGE.

Para compilar os números de óbitos, o ELAT reuniu diversos levantamentos realizados junto a órgáos de defesa civil e de dados obtidos do Ministério da Saúde. Informaçôes veiculadas na mídia também foram acompanhadas pelo ELAT.

\section{RESULTADOS E DISCUSSÃO}

Atualmente, a NASA ${ }^{7}$ é o principal órgão de pesquisa e estudos de descargas atmosféricas. Com seus dados obtidos por técnicas e equipamentos em superfície e em órbita, é possível criar um ranking com os países que apresentam as maiores ocorrências de descargas atmosféricas.

Instituto Nacional de Pesquisas Espaciais.

JAXA = Japan Aerospace Exploration Agency.

NASA - National Aeronautics and Space Administration (Administração Nacional da Aeronáutica e do Espaço). 
Figura 3 - Gráfico das ocorrências de descargas atmosféricas no mundo em 2011. Publicação: National Geographic Brasil, Fevereiro, 2012

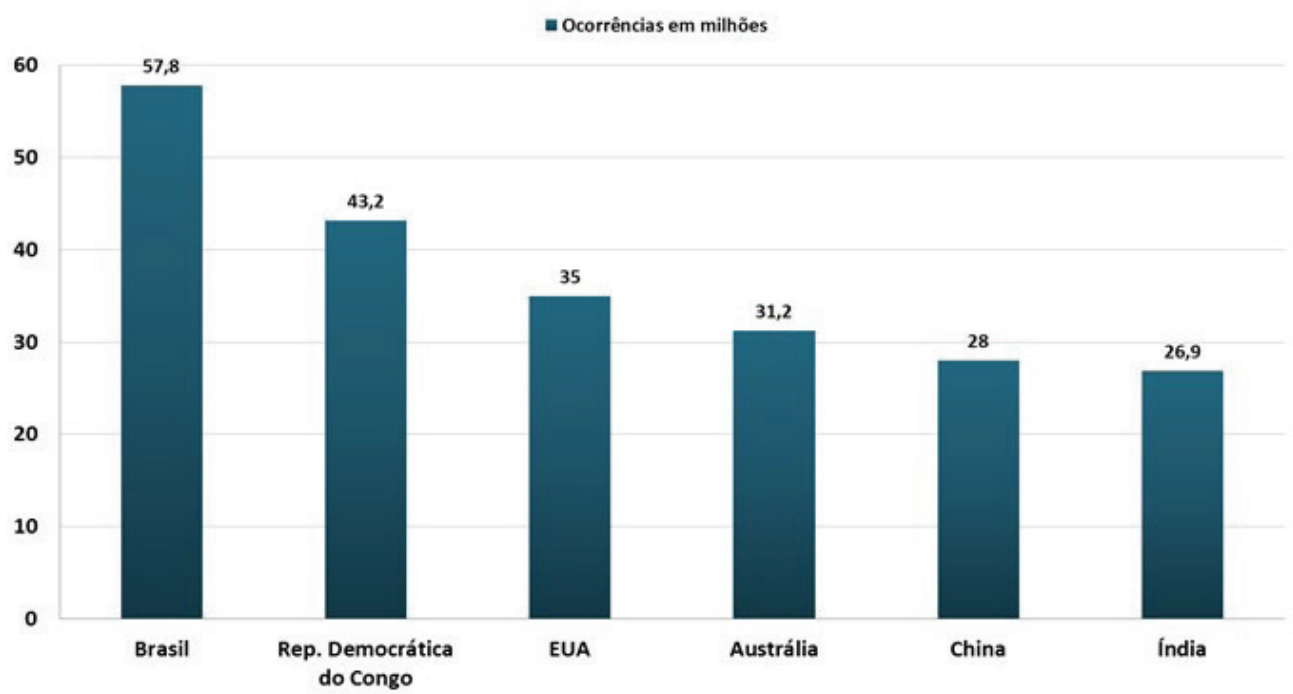

Fonte dos Dados. ELAT/INPE. Organização: BORTOLIN (2014).

As observaçóes representadas pela imagem 3 que foi obtida por um sensor denominado Lightning Imaging Sensor (LIS). Este sensor, desde 1997 até hoje, encontra-se fazendo observaçôes no espaço. Juntamente com outro sensor, o Optical Transient Detector(ODT), foram os primeiros a serem capazes de observar relâmpagos do espaço tanto de dia quanto de noite. A operaçáo do ODT encerrou - se em 2001. (PINTO JR.; PINTO, 2008).

Figura 4 - Ocorrências de descargas atmosféricas no ano de 2011

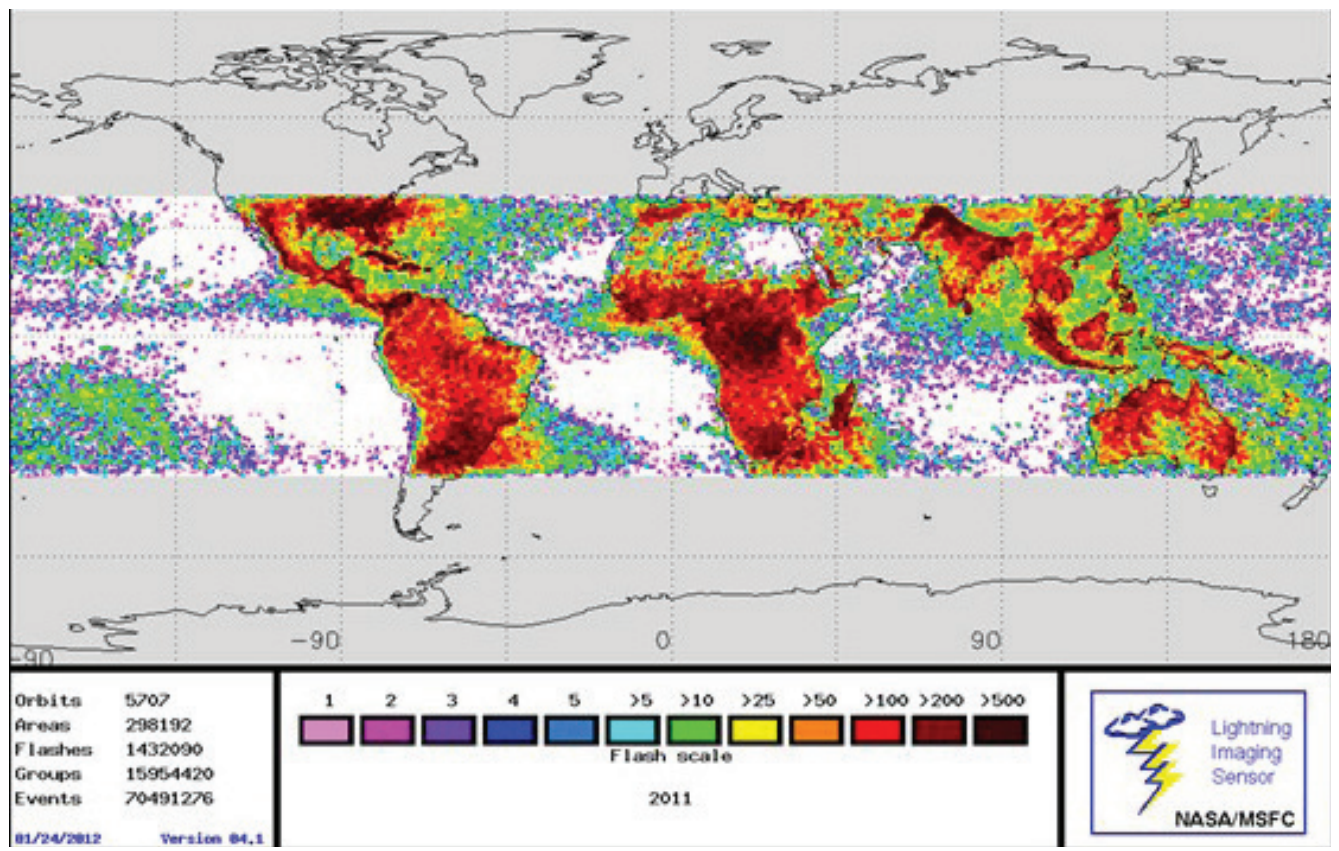

Fonte: (NASA, 2013). 
Por meio de dados obtidos através de uma publicação do INPE na revista Scientific American, o instituto apresenta um levantamento das ocorrências de óbitos no período de 2000 a 2009, em que, além de um quantitativo dos óbitos na última década, são apresentado também elementos qualitativos dessas mortes por meio de informaçóes como gênero, faixa etária mais atingida, época do ano de maiores ocorrências de fatalidades e em que locais essas mortes ocorreram com mais frequência.

É importante ressaltar que esses dados são em uma escala nacional e não somente do recorte da área de estudo. Contudo são de grande importância para entender as ocorrências, não só nas diversas regióes do país, como também na área estudada.

Figura 5 - Gráfico dos óbitos por estação

do ano no Brasil entre 2000 e 2009.

Publicação: Scientific American Brasil

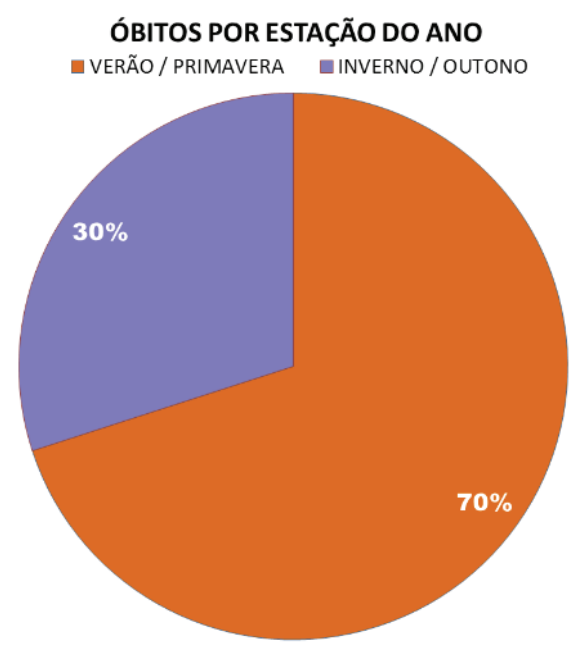

Figura 7 - Gráfico dos óbitos por faixa etária no Brasil entre 2000 e 2009.

Publicação: Scientific American Brasil

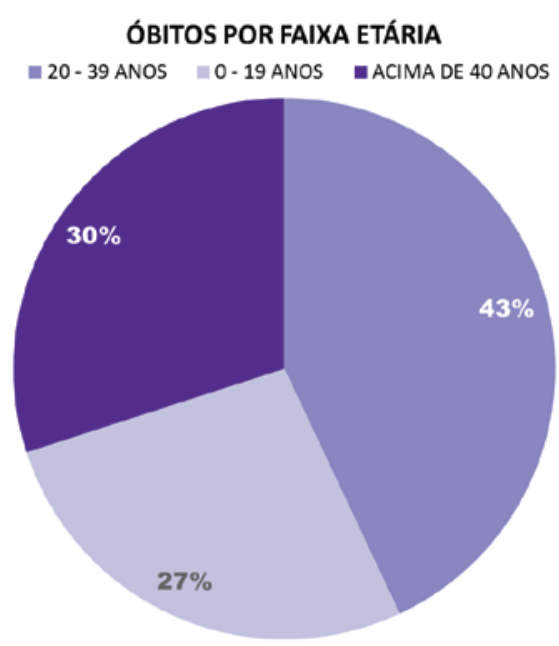

Figura 6 - Gráfico dos óbitos por gênero no Brasil entre 2000 e 2009. Publicação: Scientific American Brasil

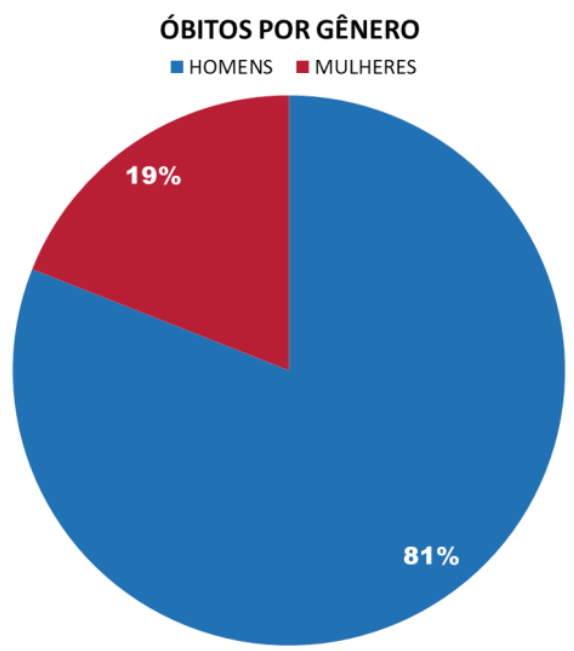

Figura 8 - Gráfico dos óbitos por localidade no Brasil entre 2000 e 2009. Publicação: Scientific American Brasil

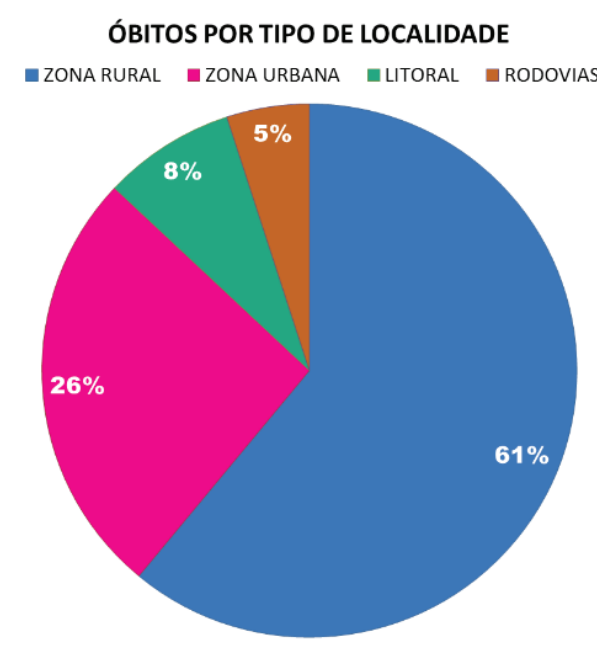

Fonte dos dados: ELAT/INPE. Organização: Bortolin (2014). 
Com base nos dados fornecidos pelo ELAT/INPE, foi construída a cartografia das incidências na área estudada (figura 9).

Figura 9 - Mapa da densidade de descargas atmosféricas na área de estudo no período de 1998 a 2011. Fonte dos dados: INPE/ELAT, 2014

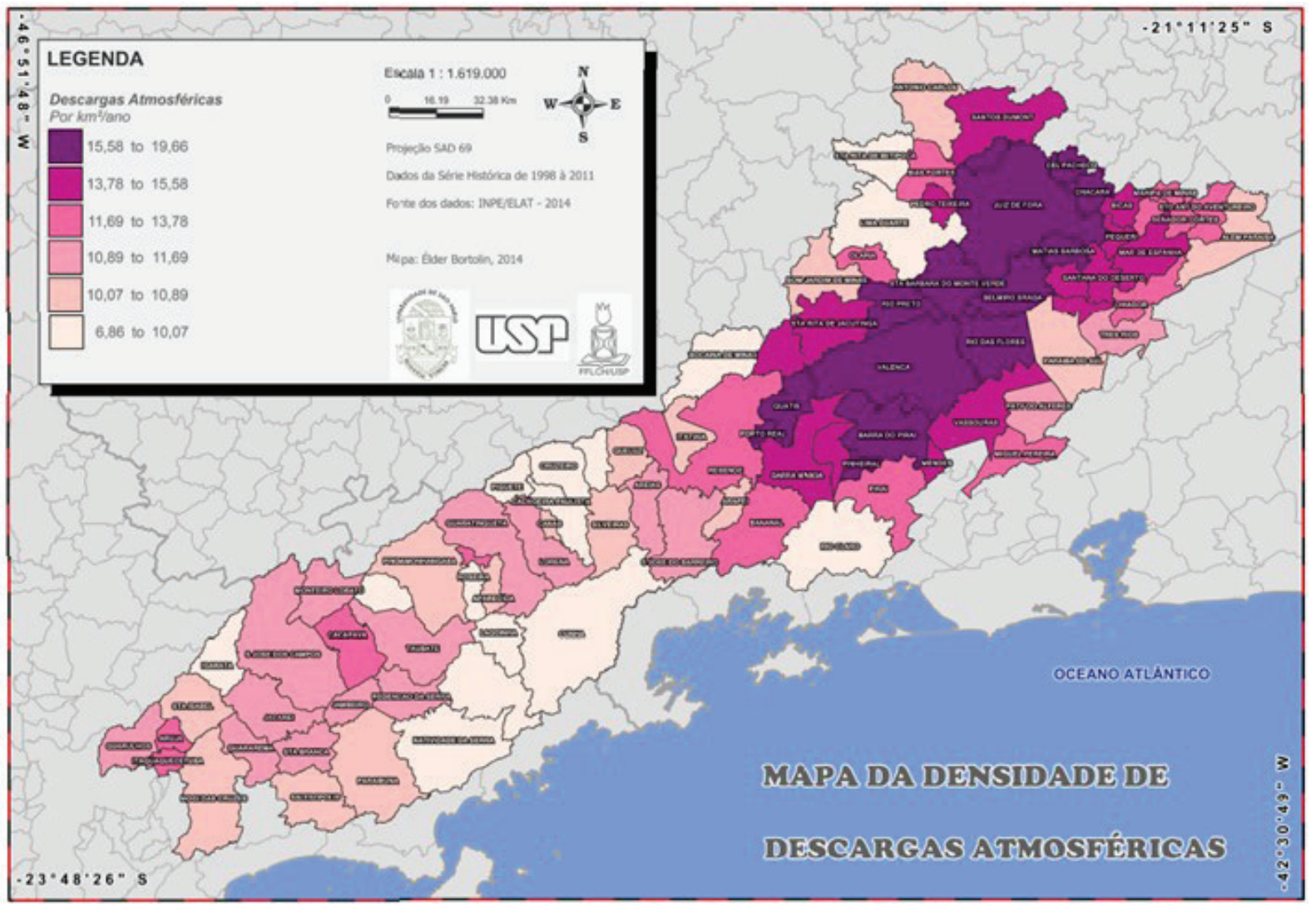

Organização: Bortolin (2014).

As ocorrências nessa área colocam os municípios situados nessa região com os maiores índices de descargas atmosférica do país no período de 1998 a 2011, a mesma série analisada e mapeada por esta pesquisa. O município de Porto Real lidera o ranking nacional apresentando uma incidência de 19,66 raios por $\mathrm{km}^{2}$ por ano.

Essas ocorrências elevadas nesse trecho da bacia podem ser explicadas, em parte, por conta do relevo, onde temos altitudes de 380 metros em Porto Real, situado em uma regiáo de planície. Os altos índices de umidade associados ao relevo de colinas na regiáo de Minas Gerais também contribuem para essas ocorrências. 
Figura 10 - Mapa dos óbitos por descargas atmosféricas na área de estudo no período de 1998 a 2011

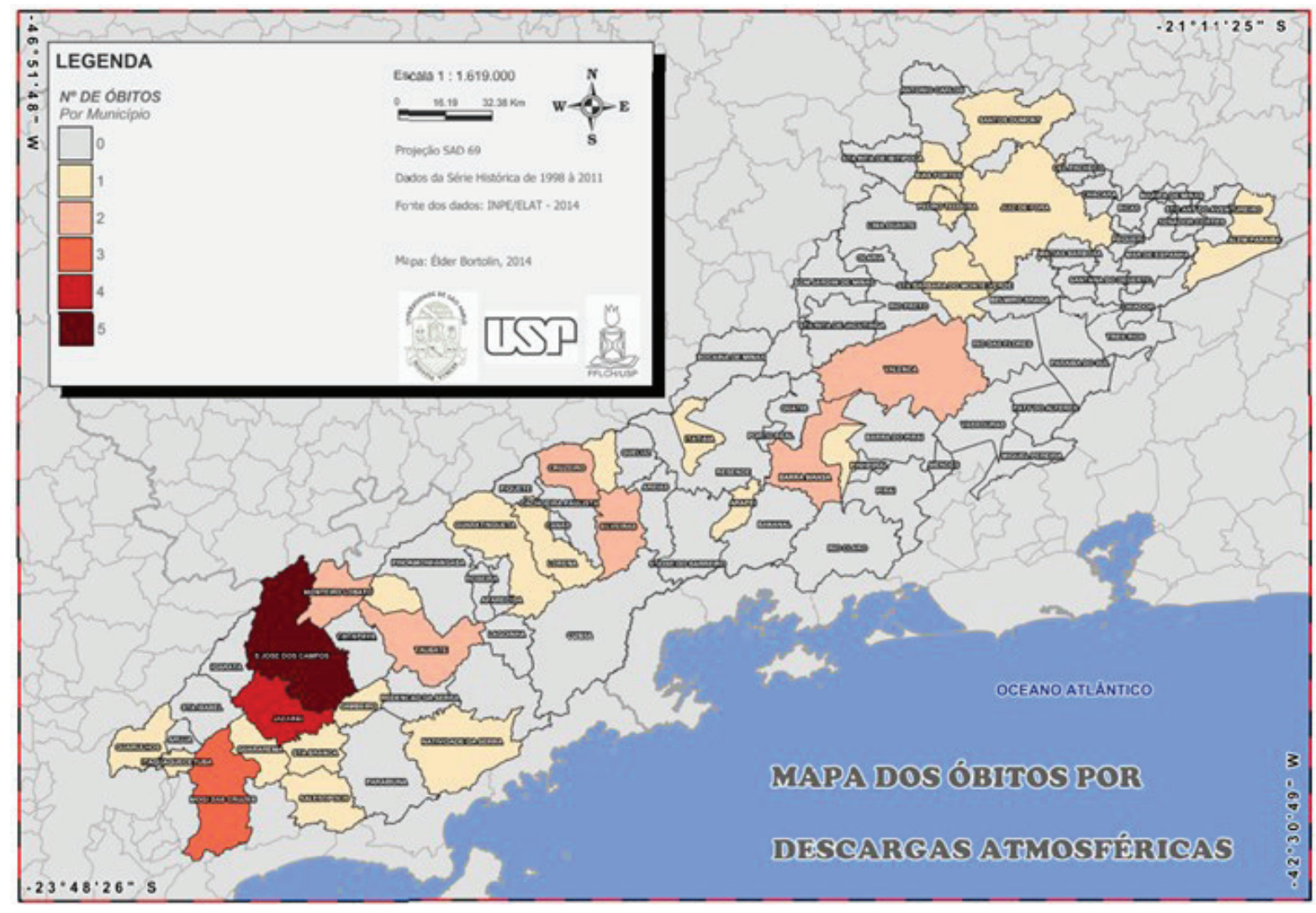

Fonte dos dados: INPE/ELAT, 2014. Organização: BORTOLIN (2014).

O mapa da figura 10 foi construído a partir dos dados de óbitos, também compilados pelo ELAT/INPE. Os resultados nos apresentam um número maior de óbitos nos municípios próximos à cidade de Sáo Paulo. Os três maiores registros da série analisada foram encontrados no município de Sáo José dos Campos (5 casos), seguido do município de Jacareí ( 4 casos) e pelo município de Mogi das Cruzes (3 casos), ambos no estado de São Paulo.

A análise dessas ocorrências de óbitos precisa levar em consideração a concentração da população e não somente a concentração de descargas atmosféricas. Para isso, temos o apoio do mapa 11, que apresenta a densidade demográfica dentro da área analisada. As áreas com maiores concentraçóes de pessoas tendem a apresentar maiores registros de óbitos. A concentração de pessoas precisa vir associada associá-la a outras características que podem variar de município para município. O perfil econômico de cada regiáo pode revelar se essa densidade demográfica se encontra mais no campo ou na cidade. Há que se considerar também os hábitos e os modos de vida das pessoas dentro das diversas localidades da área de estudo. 
Figura 11 - Mapa da densidade demográfica na área de estudo no período de 1998 a 2011

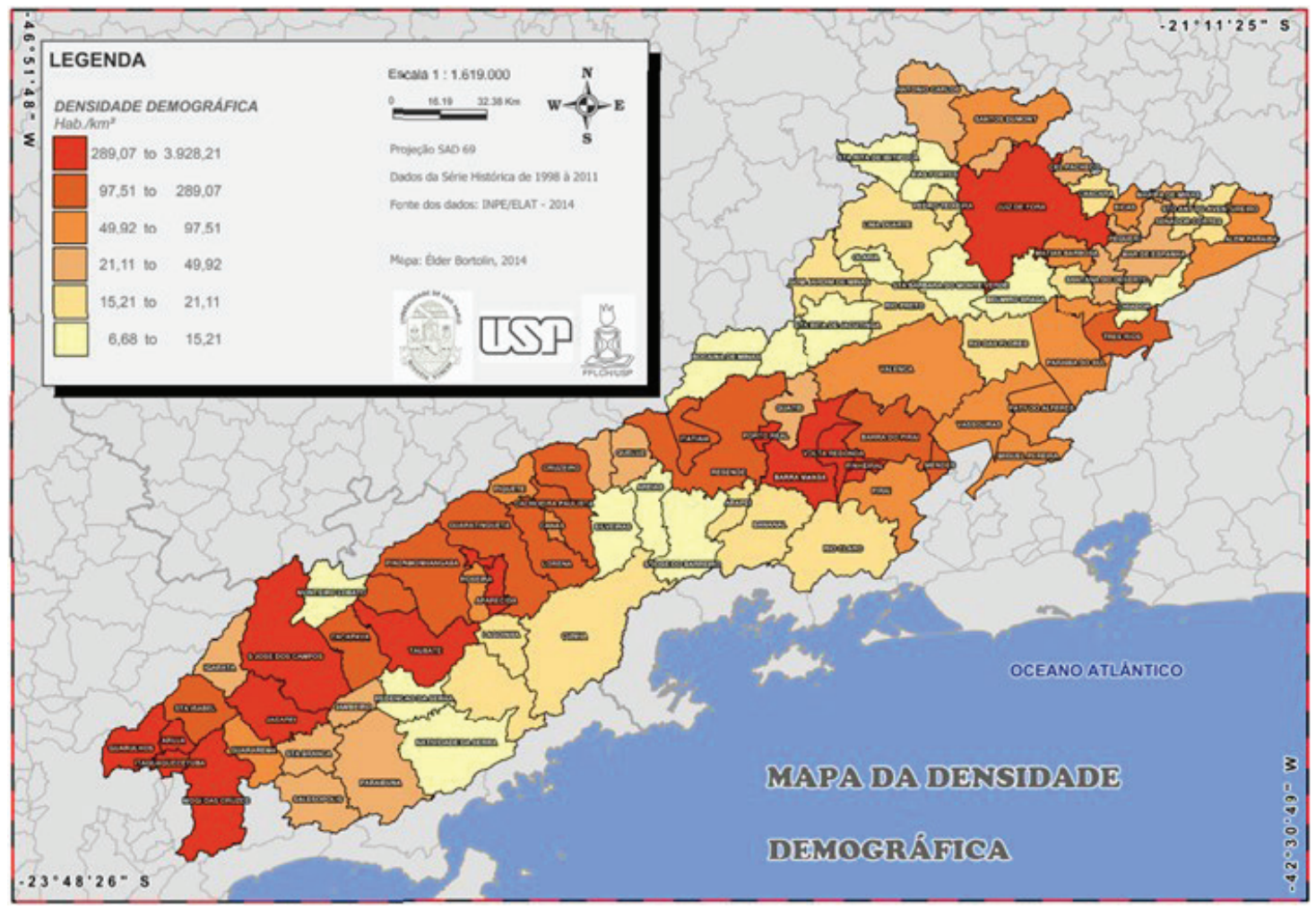

Fonte dos dados: INPE/ELAT, 2014.

A análise revela que a maior parte de óbitos por raios ocorrem nos períodos de verão e primavera, o mesmo período em que se registram os valores máximos de ocorrências de descargas atmosféricas, uma vez que são as estaçóes do ano que têm como característica um grande número de tempestades formadas por fortes processos convectivos (ELAT, 2017). As altas temperaturas atraem as pessoas para atividades de recreação em áreas abertas, principalmente para o litoral. E, embora, não seja o ambiente em que a maior parte dos óbitos foi registrada na série analisada, praticamente a totalidade das ocorrências observadas no litoral são durante os meses mais quentes do ano (ELAT, 2017).

A faixa de população mais ativa economicamente, ou seja, que muitas vezes se encontra em áreas abertas na cidade ou trabalhando no campo no momento das chuvas, é a que mais sofre com as descargas atmosféricas. Essa faixa da população com idade entre 20 e 39 anos apresenta uma porcentagem de 43\% das ocorrências de óbitos, que se eleva e representa $3 / 4$ das vítimas de relâmpagos se somarmos as ocorrências com pessoas acima de 40 anos.

Com grandes áreas abertas, na maioria das vezes com pouca vegetação arbórea e quase sempre de gramíneas, há no meio rural um grande potencial para a ocorrência de descargas atmosféricas. As poucas árvores, muitas vezes em formaçóes isoladas, cercas e 
animais soltos no pasto, são elementos com grande potencial de atração de relâmpagos. O meio rural é responsável por mais da metade dos óbitos na última década, cujas características podemos analisar no gráfico a seguir.

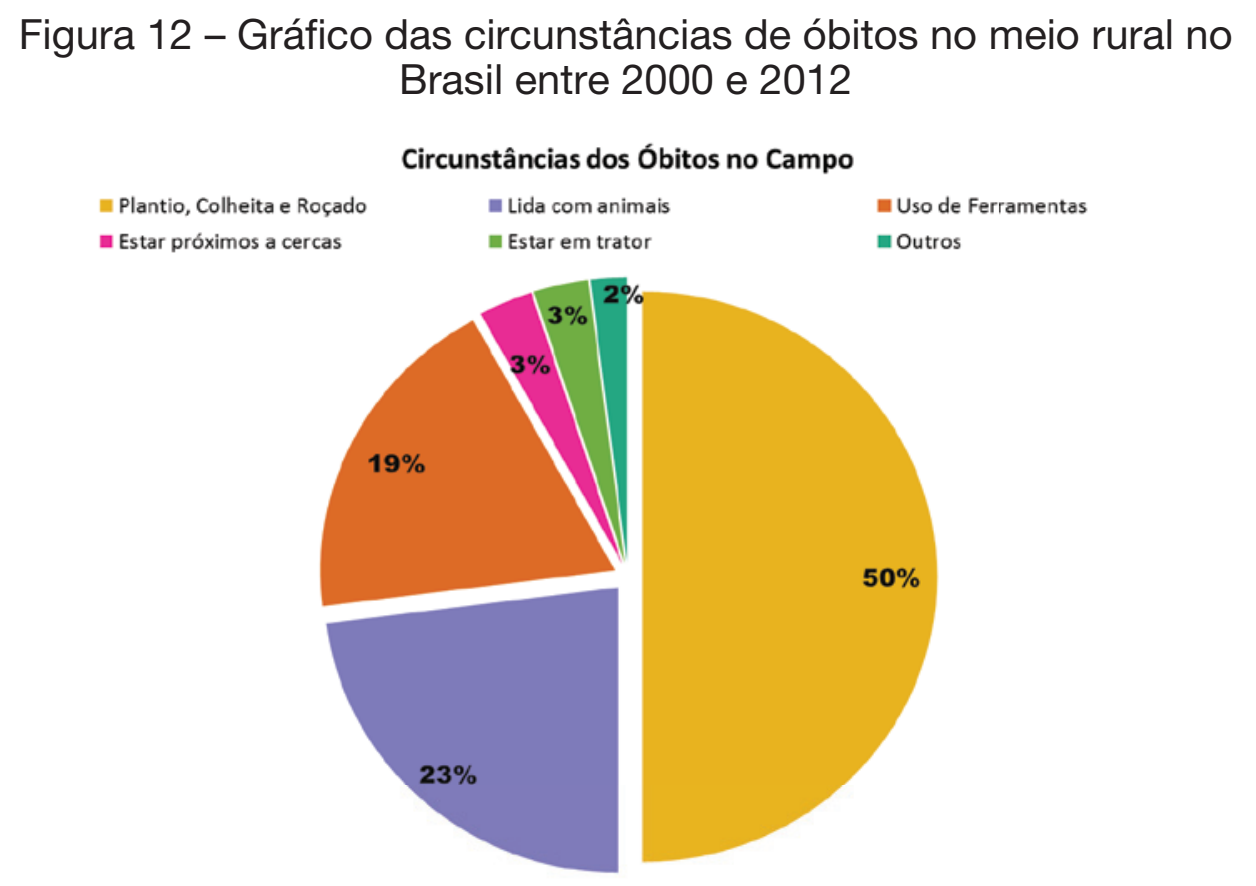

Fonte dos dados: ELAT/INPE. Organização: Bortolin (2014).

Ao analisar os dados, observa-se que $92 \%$ das circunstâncias envolvem pessoas que estáo no desenvolver de suas atividades no momento das tempestades. Sáo casos em que o trabalhador ainda se encontra no campo, em meio ao processo de plantio, colheita e roçado ou mesmo cuidando dos animais. Ou seja, além de estarem em um local aberto, as pessoas se encontravam fazendo uso de ferramentas como enxadas, foices e pás, instrumentos metálicos de trabalho que possuem um grande potencial de atrair descargas atmosféricas. Em uma tendência instintiva de tentar se proteger, o homem, assim como os animais, busca se abrigar próximo a cercas, tratores ou carroças que não oferecem nenhuma proteção e, pelo contrário, são capazes de fatalidades com muito mais facilidade.

Outras ocorrências, que embora não quantificadas com os dados apresentados, mas que causam grandes prejuízos quando se está pesquisando as relaçóes com o meio rural, são as perdas animais, tanto de gado como cavalos e outras criaçóes. Em junho de 1918, nos Estados Unidos, um único raio matou cerca de 500 ovelhas (PINTO JR.; PINTO, 2008). No Brasil, embora não se tenha um registro de quantos animais morrem anualmente, são observados casos todos os anos, como o que ocorreu em outubro de 2012 no estado do Paraná onde 30 cabeças de gado morreram em decorrência de uma descarga atmosférica e, pelo mesmo motivo, 13 bovinos morreram em fevereiro de 2013 no estado do Mato Grosso do Sul. 
O meio urbano concentra uma grande quantidade de relâmpagos devido a principalmente dois grandes elementos. Primeiramente, ao crescer, a mancha urbana avança diminuindo as áreas verdes e aumentando a superfície coberta por concreto e por asfalto, materiais que provocam um maior aquecimento dentro do meio urbano do que no seu entorno. O outro elemento está atrelado ao aumento no lançamento de partículas de poluição de origem industrial e automobilística, que facilita a formaçáo de núcleos de condensação no processo de formação de nuvens de tempestades.

O fenômeno das ilhas de calor, caracterizado pelo aumento da temperatura dos grandes centros urbanos devido ao maior adensamento das construçóes, do elevado número de prédios e área asfaltada extensa, também provoca o aumento da incidência de descargas atmosféricas nas cidades.

Ilhas de calor urbano são uma realidade identificável em diferentes períodos do ano e por meio de técnicas variadas, não apenas nas grandes cidades como São Paulo, Rio de Janeiro e Belo Horizonte, mas também em cidades de médio porte. Essas ilhas de calor ocorrem por causa do armazenamento de calor de dia pelos materiais urbanos, com devolução noturna, o que se reflete, entre outros aspectos, em aumento nas temperaturas mínimas (noites mais quentes) e diminuição na umidade relativa. Associadas a esse fenômeno estáo as alteraçóes na composição das precipitaçóes, cada vez mais acidificadas, e no padrão das distribuiçóes espacial - menos uniforme - e temporal - mais concentrada. (CAVALCANTI et al., 2009).

Devido às altas edificaçôes, a cidade tende a oferecer uma maior proteção, pois o risco de uma incidência de uma descarga atmosférica diretamente na pessoa é mais difícil. Porém, a proteção dos para-raios precisa ser entendida como limitada a uma distância de cobertura que irá depender da altura em que está instalado. A função principal de um para-raios é a proteção da estrutura predial em que ele está instalado e das pessoas que dentro dele estiverem abrigadas. A melhor proteção sempre é um ambiente fechado, portanto, pontos de ônibus, marquises, chalés ou guarda-sóis e guarda-chuvas não oferecem nenhuma proteção contra os raios.

Os casos em que as vítimas foram atingidas em rodovias representam pessoas que se encontravam expostas, seja caminhando ou em meios de transporte abertos, como bicicletas e motocicletas.

Contudo, os números de fatalidades com relação a descargas atmosféricas no Brasil vêm diminuindo nos últimos anos. Entre os principais argumentos para essa redução acredita-se em uma maior conscientização da populaçáo com relação aos perigos dos relâmpagos, principalmente nos grandes centros urbanos. Porém, as pessoas no meio rural ainda sofrem, seja com a falta de tecnologias, que em alguns casos possuem um custo financeiro muito elevado, mas, sobretudo com poucas políticas instrutivas e educativas sobre os cuidados e maneiras de protegerem suas criaçóes e se protegerem dos relâmpagos. 
Figura 13 - Gráfico do número de óbitos no Brasil de 2000 a 2015

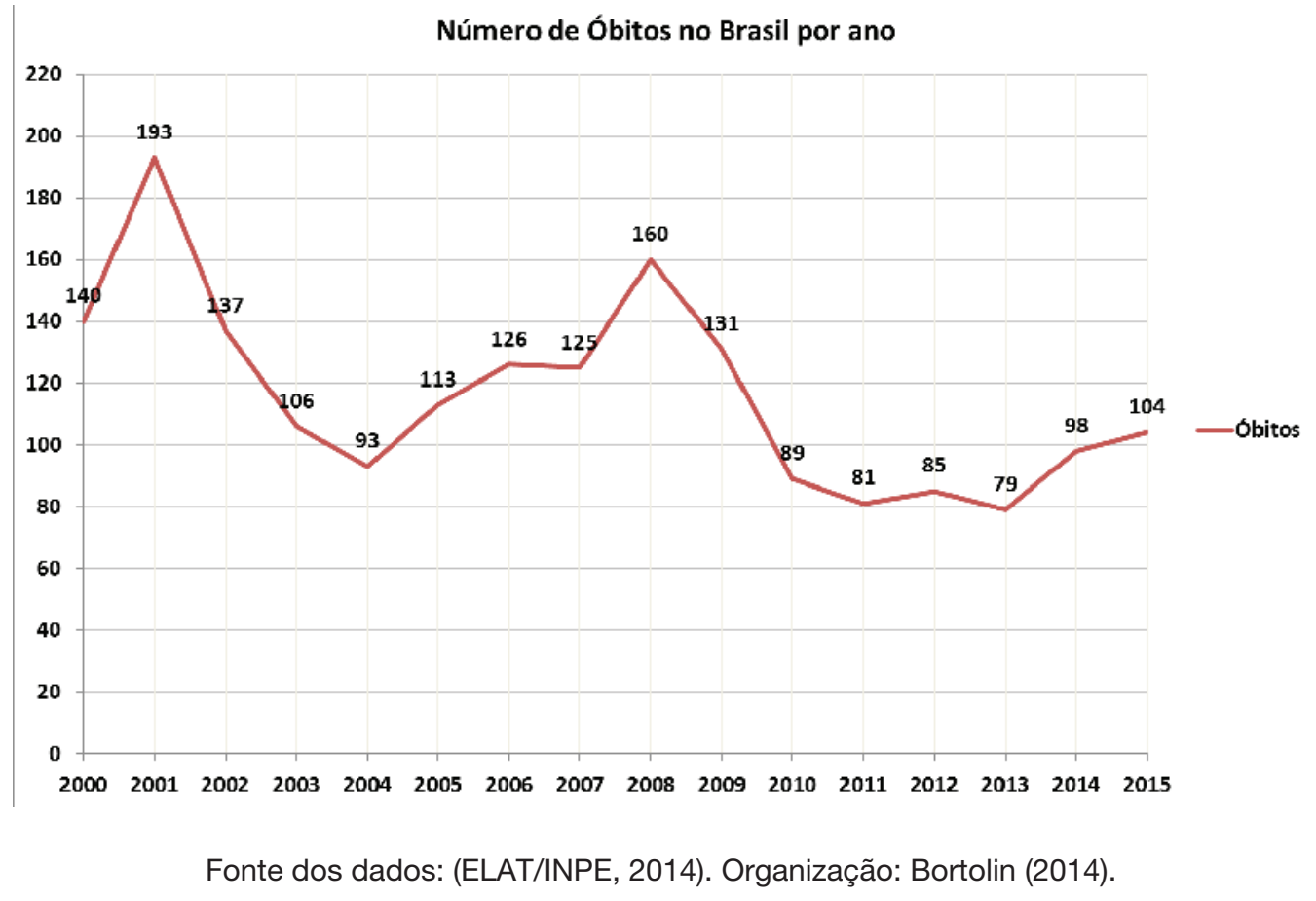

Uma grande perturbação que as descargas atmosféricas geram para a sociedade consiste nos inúmeros relâmpagos que incidem no sistema elétrico de transmissão e distribuiçấo de energia. Quando isso ocorre, pode haver a queima de transformadores e o desligamento das linhas. "No Brasil, cerca de $70 \%$ dos desligamentos na transmissáo e 40\% na distribuição, são provocados por raios, sendo o número de transformadores queimados por raios em torno de 40\%”. (INPE/ELAT, 2014). Os prejuízos para o setor elétrico no Brasil giram em torno de 600 milhóes de reais ao ano, o que representa cerca de $1 \%$ do faturamento do setor (PINTO JR.; PINTO, 2008).

\footnotetext{
"Os prejuízos no setor elétrico não se restringem à queima de equipamentos, estendendo-se a perdas de faturamento, multas e perdas relativas à sua imagem junto ao consumidor e ao mercado" (PINTO JR.; PINTO, 2008).
}

As descargas atmosféricas, devido ao grande potencial de energia que possuem, têm a capacidade de realizar a quebra de moléculas ao longo do canal, separando-as em átomos, que podem dar origem a novos elementos e com isso alterar a química na regiáo do canal. Náo são os maiores produtores de compostos nitrogenados, se considerarmos uma escala global, mas possuem uma grande influência local. Partindo da análise dessas concentraçóes, podemos observar duas grandes relaçóes: o ozônio sofre reaçóes químicas na presença de compostos nitrogenados, como o óxido de nitrogênio, que geram a sua diminuiçáo de concentraçáo na baixa estratosfera, o que permitirá uma maior incidência de radiação UV;

O nitrogênio pode ser fixado no solo também no momento do impacto do raio. Essa capacidade de fixar compostos à base de nitrogênio é essencial para os vegetais, 
uma vez que se utilizam dessas substâncias para o seu desenvolvimento e crescimento. Além dessa relação, um relâmpago pode ajudar na composição por meio da produção de incêndios, que proporcionam a reciclagem dos nutrientes do solo. Incêndios em regióes de savana e cerrado são exemplos de ocorrências desse tipo de manutenção natural.

Os impactos na superfície da Terra originados pelos raios são adversos. Ao atingir $\mathrm{m}$ solo arenoso, um raio pode produzir um mineral chamado fulgurito, que se assemelha com o vidro. A ocorrência da produção do fulgurito irá depender de como se encontra a areia no solo, quanto mais compacta maior a probabilidade de formaçáo. (INPE/ELAT, 2014).

Uma grande preocupação para os estudos climáticos está sobre as causas e o comportamento das mudanças climáticas vividas hoje em dia. O aquecimento das águas do Atlântico intensificaria a quantidade de umidade que chega ao continente, principalmente na região de influência da Massa de Ar Tropical Atlântica. Estima-se que para cada grau de aumento de temperatura aumente de $10 \%$ a $30 \%$ o número de relâmpagos no planeta (PINTO JR.; PINTO, 2008), sendo a região tropical a mais afetada.

Figura 14 - Incidência de relâmpagos da nuvem para o solo (em relâmpagos por $\mathrm{km}^{2} / \mathrm{ano}$ no Vale do Paraíba do Sul. 2008)

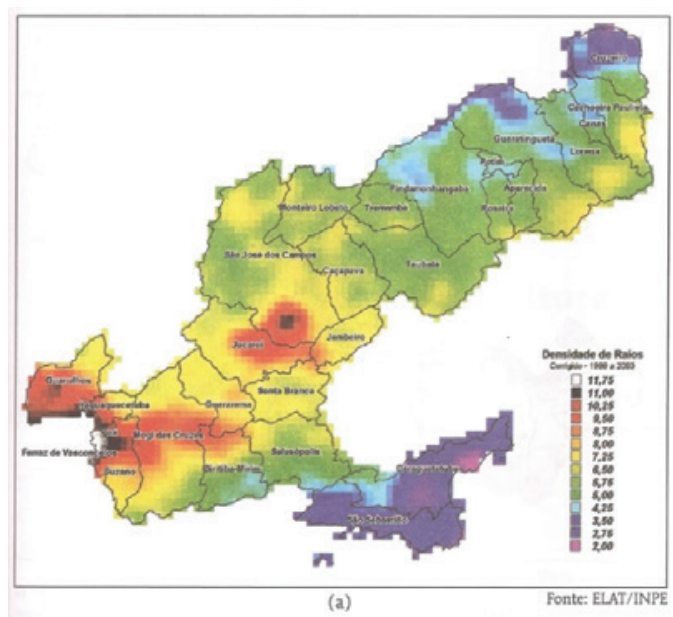

Figura 15 - Projeção da incidência de relâmpagos da nuvem para o solo (em relâmpagos por $\mathrm{km}^{2} / \mathrm{ano}$ ) para o Vale do Paraíba do Sul em 2033. Projeção obtida a partir de modelo desenvolvido pelo ELAT

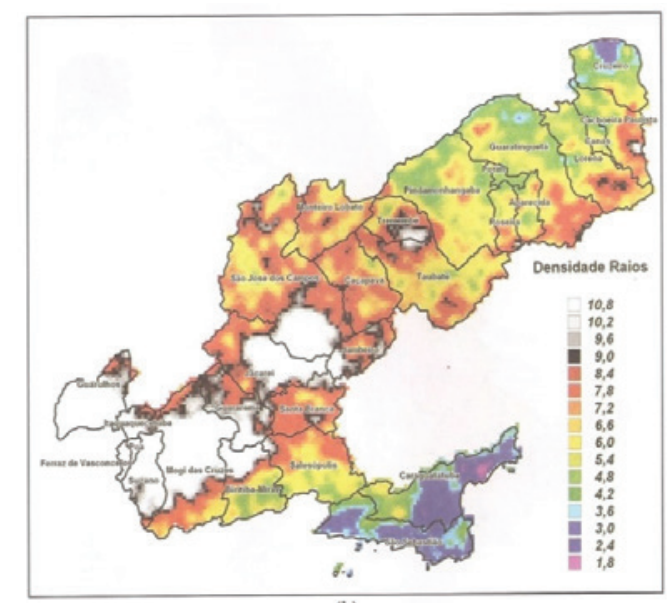

Fonte (Pinto Jr.; Pinto, 2008). 


\section{CONCLUSÓES}

Desde o final do século XIX, cientistas vêm produzindo pesquisas que indicam a possibilidade de o planeta estar aquecendo devido à crescente produçáo de $\mathrm{CO}^{2}$ sendo liberada na atmosfera pelas emissóes humanas, através da produçáo industrial, dos meios de transporte movido a queima de combustíveis fósseis, além da redução de áreas de florestas em todas as regióes do globo. Essa intensificação do efeito estufa natural da Terra foi convencionada como aquecimento global.

As expectativas, com base nas pesquisas que preveem um aquecimento do globo, independente se a causa desse aquecimento seja natural ou antrópica, apontam para um aumento da incidência de descargas atmosféricas. Portanto, conhecer de forma ampla o fenômeno ajuda a proteger a sociedade e suas atividades.

A partir dos mapeamentos realizados no recorte adotado na bacia hidrográfica do rio Paraíba do Sul, que buscou representar o número de descargas atmosféricas e o número de óbitos por relâmpagos, foi possível observar algumas relaçóes espaciais. Com o uso de ferramentas de construção de mapas digitais, foi possível especializar os dados obtidos pela internet junto ao INPE/ELAT, de relâmpagos e óbitos por descargas atmosféricas.

Essas relaçóes evidenciaram características distintas que mostram uma tendência para maiores ocorrências de descargas atmosféricas em determinadas regióes, mas que nem sempre isso está associado a um maior número de óbitos por relâmpagos. A principal causa do elevado número de óbitos por descargas atmosféricas no país ainda é reflexo de alta de conscientização da populaçãa com relação às formas de manifestação desses fenômenos elétricos da atmosfera, bem como das formas de se proteger dos mesmos. A crença em superstiçóes e mitos, tais como espelhos atraem relâmpagos e, portanto, é necessário cobri-los durante uma tempestade e a famosa afirmativa de que um raio náo cai duas vezes no mesmo lugar, leva muitas vezes as pessoas a acharem que estáo protegidas enquanto que na verdade estáo correndo os mesmos perigos, em alguns casos até se expondo mais às ocorrências dos relâmpagos.

As interaçóes entre as descargas atmosféricas e os meios naturais, como a atmosfera, solo e vegetação também foram apresentadas devido à grande importância natural ao gerar novos componentes ou até mesmo ao reciclar materiais, criando ciclos físicobiológicos. Porém, a necessidade de se conhecer melhor as descargas atmosféricas, reside nos impactos gerados na sociedade, tanto com perdas de vidas humanas quanto perdas materiais, gerando prejuízos econômicos. Por isso, o que se buscou apresentar nesta pesquisa foi uma tentativa de construir um maior entendimento da dinâmica das ocorrências de óbitos por descargas atmosféricas, o que leva a uma melhor compreensão de como os relâmpagos são vistos pela sociedade. Os avanços no entendimento de como ocorrem as fatalidades por descargas atmosféricas no país ajudam a direcionar medidas de proteção para a população. Ao entender a dinâmica das ocorrências de óbitos, é possível criar políticas de prevenção e materiais educativos voltados para a realidade nacional. Se os maiores números de óbitos ocorrem no ambiente rural, com trabalhadores do campo, é possível direcionar programas de proteção para este setor da sociedade. 


\section{REFERÊNCIAS BIBLIOGRÁFICAS}

ASSOCIAÇÃO PRÓ-GESTÃO DAS ÁGUAS DA BACIA HIDROGRÁFICA DO RIO PARAÍBA DO SUL (AGEVAP). Plano de Recursos Hídricos da Bacia do Rio Paraíba do Sul - Diagnóstico dos Recursos Hídricos; Relatório Final. Elaboração: Fundação COPPETEC, Laboratório de Hidrologia e Estudos de Meio Ambiente. PSR-010-R0 / Novembro - 2006.

CARDOSO, I. Os Números (SURPREENDENTES) de Mortes por Raios no Brasil. Scientific American, ed. $\mathrm{n}^{\circ}$ 110, Julho de 2011. Disponível em: http:/www2.uol.com.br/ sciam/reportagens/os_numeros_surpreendentes_de_mortes_por_raios_no_brasil.html. Acesso em 25 de Novembro de 2013.

CAVAlCANTI, Iracema F. A. (Org.). Tempo e clima no Brasil. São Paulo: Oficina de Textos, 2009.

COMITÊ DE INTEGRAÇÃO DA BACIA HIDROGRÁFICA DO RIO PARAÍBA DO SUL (CEIVAP). Dados Gerais. http://www.ceivap.org.br/dados-gerais.php. Acesso em 28 de Janeiro de 2017

CONTI, J. B. Circulação secundária e efeito orográfico na gênese das chuvas na região lesnordeste paulista. Doutorado, Universidade de São Paulo, Instituto de Geografia, São Paulo, 1975.

INPE, Instituto Nacional de Pesquisas Espaciais. ELAT, Grupo de Eletricidade Atmosférica. Ponto de Vista/Editorial ELAT n ${ }^{\mathbf{0}}$.

http://www.inpe.br/webelat/homepage/menu/noticias/editorial.php?id=8. Acesso em $4 \mathrm{de}$ abril de 2014.

INPE, Instituto Nacional de Pesquisas Espaciais. ELAT, Grupo de Eletricidade Atmosférica. Ocorrências na Terra.

http://www.inpe.br/webelat/homepage/menu/relamp/relampagos/ocorrencia.na.terra.php. Acesso em 21 de outubro de 2013.

INPE, Instituto Nacional de Pesquisas Espaciais. ELAT, Grupo de Eletricidade Atmosférica. Aquecimento Global.

http://www.inpe.br/webelat/homepage/menu/infor/relampagos.e.efeitos/aquecimento. global.php. Acesso em 21 de outubro de 2013.

INPE, Instituto Nacional de Pesquisas Espaciais. ELAT, Grupo de Eletricidade Atmosférica. Solo.http://www.inpe.br/webelat/homepage/menu/infor/relampagos.e.efeitos/solo.php. Acesso em 21 de outubro de 2013.

INPE, Instituto Nacional de Pesquisas Espaciais. ELAT, Grupo de Eletricidade Atmosférica. Núcleo de Monitoramento de Descargas Atmosféricas.

http://nucleo.tempestades.org.br/tempestades.org.br/webnucleo/homepage/menu/mortes.por.descargas.atmosfericas/mortes.por.descargas.atmosfericas.php. Acesso em 21 de Outubro de 2013. 
INPE, Instituto Nacional de Pesquisas Espaciais. ELAT, Grupo de Eletricidade Atmosférica. Release ELAT No 39.

http://www.inpe.br/webelat/homepage/menu/noticias/release.php?id=70. Acesso em $28 \mathrm{de}$ Janeiro de 2017.

MACGORMAN, D. R.; RUST, W. D. The Electrical Nature of Storms. New York, USA: Oxford University Press, 1998.

MENDES JR., O; DOMINGUES, M. O. Introduction to the atmospheric electrodynamics. Revista Brasileira de Ensino de Física, v. 24, n. 1, p. 3-19, 2002.

NACCARATO, K. P. Estudo de relâmpagos no Brasil com base na análise de desempenho do Sistema de Localização de Tempestades. 2001. 165p. (INPE-8380- TDI/770). Dissertação (Mestrado em Geofísica Espacial) - Instituto Nacional de Pesquisas Espaciais, São José dos Campos. 2001. Disponível na biblioteca digital URLib: http://mtc-m05.sid. inpe.br:80/rep-/dpi.inpe.br/lise/2002/03.28.19.09. Acesso em: 31 mar. 2014

NACCARATO, K. P. Análise das características dos relâmpagos na região sudeste do Brasil. - São José dos Campos: Instituto Nacional de Pesquisas Espaciais (INPE), 2005.

NASA, National Aeronautics and Space Administration. Lightning and Atmospheric Electricity Research at the GHCC/ LIS Global Lightning Distributions.

$\mathrm{ftp} / /$ ghrc.nsstc.nasa.gov/pub/browse/lis/lis-summaries/2011/2011.png, acesso em 14 de janeiro de 2014.

PINTO, I. A.; PINTO JR., O. Relâmpagos. 2. ed. São Paulo: BRASILIENSE, 2008.

RAKOV, Vladimir A.; UMAN, Martin A. Lightning: Physics and Effects. New York, USA: Cambridge University Press, 2003.

ROSS, J. L. S. (Org.). Geografia do Brasil. São Paulo: EdUSP, 1996.

SÃO PAULO (Estado). Secretaria do Meio Ambiente. Subsídios ao planejamento ambiental da unidade hidrográfica de gerenciamento de recursos hídricos Paraíba do Sul: UGRHI 02 [recurso eletrônico] / Secretaria do Meio Ambiente do Estado de São Paulo, Coordenadoria de Planejamento Ambiental; Organização Márcia Renata Itani... [et al.]; Equipe técnica Alana Almeida de Souza ... [et al.] ; Colaboradores Alberto Cavalcanti de Figueiredo Netto ... [et al.]. - Sáo Paulo: SMA, 2011. 